\title{
IMPACTS OF TRANSGENIC PLANTS AND MICRO- ORGANISMS ON SOIL BIOTA
}

\author{
M. O'CALLAGHAN and T.R. GLARE
}

Biocontrol and Biosecurity, AgResearch, PO Box 60, Lincoln

Corresponding author: maureen.ocallaghan@agresearch.co.nz

\section{ABSTRACT}

Little is known about the impacts of transgenic plants and micro-organisms on soil biota and processes, despite the large number of field releases of transgenic crops. Recent work has shown that transgenic plants can cause changes in the soil biota (both invertebrates and micro-organisms) associated with these plants. Often the changes are transient but their impact on the soil ecosystem remains unknown. Horizontal gene transfer from genetically modified (GM) bacteria to indigenous soil bacteria has been demonstrated but movement of genes from transgenic plants, if it occurs at all, has not yet been detected in natural systems. Soil invertebrates appear to play an important role in horizontal gene transfer between bacteria in soil.

Keywords: transgenic plants, transgenic micro-organisms, soil ecosystem, environmental impacts, horizontal gene transfer.

\section{INTRODUCTION}

While efforts have been made to examine the environmental impacts of genetically modified (GM) plants "above ground", comparatively little research has been directed at impacts of genetically modified organisms (GMOs) on soil organisms and processes, perhaps because of the greater difficulties involved in the study of soil invertebrates and micro-organisms. However, soil biota play a vital role in mineralization and immobilization of nutrients, physical and biochemical degradation of organic matter, biological control of plant pests and as food sources for other organisms. Evaluation of the potential impacts of GMOs on soil ecosystems is therefore essential.

Concerns about impacts of GMOs on soil biota have been raised, in part because of the chemical and biological properties of soil (MacGregor \& Turner 2000). Soil materials have large sorptive capacities for biological molecules, including DNA and insecticidal bacterial proteins. There is increasing scientific data to show that soil can, in some cases, protect these molecules from biological degradation, enabling their toxic properties and genetic information to be retained in soil for unexpectedly long periods. There are also concerns that biological nutrient cycling could be affected.

The impact of GMOs on non-target soil biota will depend on the nature of the recombinant protein (i.e. its spectrum of activity) and the extent of exposure. GM plants release exudates and decompose in soil. Determination of the stability and persistence of the transgenic material in soil is a key factor in determining the effect on non-target soil organisms. While the persistence of Bacillus thuringiensis $(\mathrm{Bt})$ toxins in soil has been studied (Stotzky 2000), virtually nothing is known about the fate of other transgenic proteins released into soil as GM plants shed leaves or decompose.

It has been suggested that the introduction of bacterial genes into the plant genome could lead to increased probability of gene transfer events from transgenic plants to bacteria (Droge et al. 1998). Transfer of genetic information from GM plants and GM micro-organisms to indigenous micro-organisms is of public concern as it provides a pathway for changes in genotypic diversity of the microbiota. It is not known whether such changes in genotypic diversity occurring through horizontal gene transfer (HGT) could result in unanticipated changes in the phenotypic 
expression of the recipient micro-organism(s) that could have a detrimental impact on the environment.

This paper highlights some recent work on non-target impacts of GMOs on soil invertebrates and micro-organisms, including direct effects on populations, and the potential for HGT from transgenic plants and micro-organisms to indigenous bacteria in soil.

\section{EFFECTS ON NON-TARGET SOIL DWELLING ORGANISMS}

\section{Impacts of genetically modified plants}

Recent studies have started to examine the possible impacts of GM plants on soil biota important in the breakdown of organic matter and nutrient cycling in soil. Griffiths et al. (2000) found transient reductions in the soil protozoan populations exposed to GM potatoes expressing lectins. In field release experiments, GM potatoes consistently altered the physiological profile of the rhizosphere microbial community at harvest, but the effect did not persist from one season to the next.

Other studies have also demonstrated changes in various components of the soil biota in response to GM plants. Siciliano \& Germida (1999) reported differences in the composition of the rhizosphere microbial communities between canola (rape) modified to confer resistance to glyphosate and unmodified isogenic canola. Donegan et al. (1997) observed differences in nematode population density and trophic structure associated with transgenic tobacco leaf litter, which may have reflected differences in the carbon content in the GM and non-GM plants. Differing composition of the leaves may have caused differences in the microbiota utilizing the substrate, which in turn may have influenced nematode populations developing on the microflora. Unexpected changes in plant characteristics as a result of the transformation process have been reported in several other studies (e.g. Donegan et al. 1999; Escher et al. 2000; Hopkins et al. 2001). Changes in the nutritional status of GM plants compound the difficulties in interpreting putative impacts of transgenes on soil biota and there is a clear need for appropriate controls in such experiments.

\section{Impacts of genetically modified micro-organisms}

Impacts of GM micro-organisms released into soil have been less well studied, as there have been fewer field releases of GM micro-organisms. Ecological effects resulting from introduction of GM micro-organisms into terrestrial environments include the ability of the GM micro-organisms to compete successfully with the indigenous microbiota; transfer of genes to new hosts; changes in biomass turnover; and changes in community structure and function of the indigenous microbiota (Doyle et al. 1995). However, these effects have mainly been observed in laboratory studies and may not necessarily reflect the situation in the field.

Several studies, including field releases, have been made using GM micro-organisms carrying genetic markers which allow the selective recovery of the released strain from the environment. Transient changes in composition of the indigenous soil microflora have often been reported following their inoculation into soil (e.g. de Leij et al. 1995) but often changes have not been significantly different from responses to inoculation of the wildtype strain. Indeed, these genetically marked strains have been designed to differ as little as possible from the wildtype strain and, as they are not functionally modified, little perturbation of the ecosystem would be expected. There have been relatively few studies examining the impacts of functionally modified bacteria. One recent example is the study by Giddings et al. (2000), who showed that Rhizobium leguminosarum, modified with a beetle-active Bt gene for protection from Sitona weevil damage, unexpectedly had an increased ability to compete for nodule sites on pea roots. While growth rates of the GM strain and the wildtype were the same in laboratory media, the GM strain exhibited an ecological advantage over the wildtype strain when inoculated into soil with pea plants. The reasons for this advantage have not yet been explained but do not appear to be associated with the intended function of the transgene and may be a secondary effect resulting from alteration caused by random site of insertion of the new gene. 


\section{HORIZONTAL GENE TRANSFER}

As plants do not have any identified mechanism to facilitate broad host range gene transfer (except for pollen hybridisation with related species), the possibilities and barriers to HGT from transgenic plants to bacteria must be approached from the framework of known mechanisms of HGT within bacteria. Various mechanisms of HGT in bacteria have been described, only two of which are considered in this contribution.

\section{Natural transformation}

Transformation is considered the most likely pathway by which genes may be passed from plants to micro-organisms in the environment. Evolutionary transfer of genetic information from plants to bacteria has been inferred from nucleotide sequence comparisons (Droge et al. 1998). In this process, the bacterial cell incorporates naked DNA taken up from the surrounding medium. To take up DNA from the environment, the bacterium must be in a state of competence. Conditions for competency vary between bacterial species. Both plasmids and chromosomal DNA may be taken up by transformation. Donor DNA may come from DNA released from live organisms or leaked from dead organisms. There are many barriers to transformation in soil (Nielson et al. 1998) and rates of transformation in soil are assumed to be extremely low. Although it was initially thought that DNA was rapidly degraded in soil, recent studies have shown that DNA can persist in soil under certain conditions for months to years (Gebhard \& Smalla 1999). Recent work has also shown that more species of bacteria are capable of transformation than previously thought (Havarstein 1998), and Demaneche et al. (2001) have recently shown that natural transformation of Pseudomonas fluorescens and Agrobacterium tumefaciens can take place in soil microcosms but transformation could not be detected under in vitro conditions.

Efforts to demonstrate gene transfer from transgenic plants to micro-organisms experimentally, by screening environmental isolates found in association with transgenic crops have proved unsuccessful to date. Despite screening 4000 bacterial colonies, Gebhard \& Smalla (1999) did not detect movement of the kanamycin resistance gene from transgenic sugar beet to indigenous soil bacteria. However, they concluded that the likelihood of detecting transformation was reduced by the natural occurrence of high numbers of kanamycin resistant bacteria in the environment.

Until recently it has been unclear whether bacteria can be transformed by plant DNA at all. Recent attempts to demonstrate HGT from transgenic plants experimentally have focussed on the use of model systems, where the micro-organism chosen as the recipient for the transgenic DNA is naturally competent. Transformation of recipient bacteria has been shown in studies (reviewed in Droge et al. 1998) conducted under optimised laboratory conditions, using plant DNA with known homology to the recipient. Compared to transformation with chromosomal or plasmid DNA, transformation frequencies with plant DNA or plant homogenates were significantly reduced when experiments conducted by filter transformation were taken a step further and performed in sterile and nonsterile soil. Transformation of a strain of soil bacterium Acinetobacter sp. by transgenic sugar beet DNA could be detected in sterile but not in non-sterile soil (Nielsen et al. 2000). The frequency of transformation in non-sterile soil was estimated at $10^{-10}$ to $10^{-11}$ and was therefore below the level of detection. Other experiments have confirmed the low probability of integration of transgenes in the bacterial genome if DNA homology is not present (Nielsen et al. 1997). Present data suggest that transformation of competent bacteria by transgenic plant DNA in soil and in the rhizosphere occurs, if at all, at very low frequencies.

\section{Conjugation}

Conjugation may occur between closely related bacterial species, between different genera and even between Gram positive and Gram negative bacteria. DNA transfer from one bacterial cell to another can occur with direct contact between cells. DNA is transferred through specialised conjugation structures which are encoded by various self-transmissible plasmids and conjugative transposons. The reported rates of conjugation between bacteria in soil vary widely. While it is often possible to demonstrate plasmid transfer at high rates in vitro, the rate generally decreases significantly when 
experiments are conducted in soil. However, within soil there are known "hotspots" where conjugation occurs at higher rates, for example in the plant rhizosphere. Movement of plasmids from GM micro-organisms to indigenous soil bacteria has been demonstrated (Smit et al. 1991) and uptake of plasmids by GM micro-organisms from indigenous bacteria has also been observed (Lilley \& Bailey 1997), demonstrating the considerable potential for HGT in soil.

Recent work has shown that soil biota can play an important role in HGT in soil. Daane et al. (1997) showed that conjugation between spatially separated donor and recipient bacteria only occurred in soil microcosms containing earthworms. Moreover, in some insects, the gut provides suitable conditions for growth and conjugation by bacteria. Contact between micro-organisms is also increased as large bacterial populations are confined within the small volume of the alimentary tract. Conjugation between bacteria has been reported in the gut of Rhabditis nematodes (Adamo \& Gealt 1996), Collembola (Hoffman et al. 1999), and in the New Zealand grass grub (S. Dodd \& M. O'Callaghan, unpubl. data). Conjugation rates recorded in insects can approach the rates measured in vitro.

\section{DISCUSSION}

This review of the impacts of GMOs on the soil biota and processes demonstrates the current paucity of scientific knowledge available to support risk assessment of GMOs. Laboratory and limited field experimentation has shown that transgenic plants and microorganisms introduced into soil have sometimes caused statistically significant changes in the structure and function of indigenous soil biota. However, because of the transient nature of some of these documented responses, it is difficult to distinguish between the "statistical" and "ecological" significance of measured responses. Consequently, in some cases, the determination of ecological significance continues to be based on the intuitive judgement of the researcher.

The effects of genetic modification on interactions between components of the soil/ plant system may not be evident in vitro. In some cases, secondary (unexpected) effects of genetic modification would not have been detected without assessment under experimental conditions similar to those in natural soils. As microbial and invertebrate populations can be highly variable in soil, there is a clear need for robust experimental design to overcome some of the complexities associated with soil biota assessments. Appropriate controls must be included, to allow differentiation between effects of the genetic modification process and the impacts of the transgene itself on non-target organisms.

In contrast to knowledge about HGT by conjugation in soil, less is known about the importance of transformation processes in environmental habitats. It cannot be excluded that HGT from plants to bacteria by transformation may take place in certain environmental niches, such as the digestive gut of soil insects, which have been suggested as optimal for gene transfer events (e.g. Hoffman et al. 1999). However, the ecological significance of such rare events depends on the selection of the acquired trait. If transfer of novel genes to bacteria provided transformants with a selective advantage or ability to occupy a new niche, multiplication of the bacterium and its transgene could be expected. However, the present knowledge of microbial ecology in soil environments is unable to predict and quantify those factors in soil that affect the selection of bacterial transformants receiving novel genes (Nielsen et al. 1998).

Despite difficulties with the interpretation of experimental results, the occurrence of some ecological perturbations induced by GMOs suggests that until methods and theories for establishing ecological significance are developed and verified, the potential ecological impacts of GMOs released into the environment will need to be evaluated on a case by case basis. The frequency of reports of detectable changes in soil biota is perhaps somewhat unexpected, given that research into this area has only recently begun. The long-term implications of these changes in soil must be assessed. 


\section{ACKNOWLEDGEMENTS}

We are grateful to Drs S.L. Goldson and T.A. Jackson for helpful comments on the manuscript.

\section{REFERENCES}

Adamo, J.A.; Gealt, M.A. 1996: A demonstration of bacterial conjugation within the alimentary canal of Rhabditis nematodes. FEMS Micro. Ecol. 20: 15-22.

Daane, L.L.; Molina, J.A.E.; Sadowsky, M.J. 1997: Plasmid transfer between spatially separated donor and recipient bacteria in earthworm-containing soil microcosms. Appl. Enviro. Micro. 63: 679-686.

De Leij, F.A.A.M.; Sutton, E.J.; Whipps, J.M.; Fenlon, J.S.; Lynch, J.M. 1995: Impact of field release of genetically modified Pseudomonas fluorescens on indigenous microbial populations of wheat. Appl. Enviro. Micro. 61: 3443-3453.

Demaneche, S.; Kay, E.; Gourbiere, F.; Simonet, P. 2001: Natural transformation of Pseudomonas fluorescens and Agrobacterium tumefaciens in soil. Appl. Enviro. Micro. 67: 2617-2621.

Donegan, K.K.; Seidler, R.J.; Fieland, V.J.; Schaller, D.L.; Palm, C.J.; Ganio, L.M.; Cardwell, D.M.; Steinberger, Y. 1997: Decomposition of genetically engineered tobacco under field conditions: persistence of the proteinase inhibitor I product and effects on soil microbial respiration and protozoa, nematode and microarthropod populations. J. Appl. Ecol. 34: 767-777.

Donegan, K.K.; Seidler, R.J.; Doyle, J.D.; Porteous, L.A.; Digiovanni, G.; Widmer, F.; Watrud, L.S. 1999: A field study with genetically engineered alfalfa inoculated with recombinant Sinorhizobium meliloti: effects on the soil ecosystem. J. Appl. Ecol. 36: 920-936.

Doyle, J.D.; Stotzky, G.; McClung, G.; Hendricks, C.W. 1995: Effects of genetically engineered microorganisms on microbial populations and processes in natural habitats. Adv. Appl. Microbiol. 40: 237-287.

Droge, M.; Puhler, A.; Selbitschka, W. 1998: Horizontal gene transfer as a biosafety issue: A natural phenomenon of public concern. J. Biotechnol. 64: 75-90.

Escher, N.; Kach, B.; Nentwig, W. 2000: Decomposition of transgenic Bacillus thuringiensis maize by microorganisms and woodlice Porcello scaber (Crustacea: Isopoda). Basic Appl. Entomol. 1: 161-169.

Gebhard, F.; Smalla, K. 1999: Monitoring field releases of genetically modified sugar beets for persistence of transgenic plant DNA and horizontal gene transfer. FEMS Micro. Ecol. 28: 261-272.

Giddings, G.; Mytton, L.; Taylor, L.; Thomas, S.; Allen, D.; Skot, L. 2000: A secondary effect of transformation in Rhizobium leguminosarum transgenic for Bacillus thuringiensis subspecies tenebrionis delta-endotoxin (cryIIIA) genes. Part 2. Theoret. Appl. Genet. 100: 820-823.

Griffiths, B.S.; Geoghegan, I.E.; Robertson, W.M. 2000: Testing genetically engineered potato, producing lectins GNA and Con A, on non-target soil organisms and processes. J. Appl. Ecol. 37: 159-170.

Havarstein, L.S. 1998: Bacterial gene transfer by natural genetic transformation. Acta Path. Micro. Immunol. Scand. 106: 43-46.

Hoffmann, A.; Thimm, T.; Tebbe, C.C. 1999: Fate of plasmid-bearing, luciferase marker gene tagged bacteria after feeding to the soil microarthropod Onychiurus fimatus (Collembola). FEMS Microbiol. Ecol. 30: 125-135.

Hopkins, D.W.; Webster, E.A.; Chudek, J.A.; Halpin, C. 2001: Decomposition in soil of tobacco plants with genetic modifications to lignin biosynthesis. Soil Biol. Biochem. (in press).

Lilley, A.K.; Bailey, M.J. 1997: The acquisition of indigenous plasmids by a genetically marked pseudomonad population colonising the sugarbeet phytosphere is related to local environmental conditions. Appl. Enviro. Micro. 63: 1577-1583. 
McGregor, A.N.; Turner, M.A. 2000. Soil effects of transgenic agriculture: biological processes and ecological consequences. N.Z. Soil News 48(6): 166-169.

Nielsen, K.M.; Gebhard, F.; Smalla, K.; Bones, A.M.; van Elsas, J.D. 1997: Evaluation of possible horizontal gene transfer from transgenic plants to the soil bacterium Acinetobacter calcoaceticus BD413. Theor. Appl. Genet. 95: 815-821.

Nielsen K.M.; Bones, A.M.; Smalla, K.; van Elsas, J.D. 1998: Horizontal gene transfer from transgenic plants to terrestrial bacteria - a rare event? FEMS Microbiol. Rev. 22: 79-103.

Nielsen, K.M.; van Elsas, J.D.; Smalla, K. 2000: Transformation of Acinetobacter sp. strain BD413 (pFG4-nptII) with transgenic plant DNA in soil microcosms and effects of kanamycin on selection of transformants. Appl. Environ. Micro. 66: 12371242.

Siciliano, S.D.; Germida, J.J. 1999: Taxonomic diversity of bacteria associated with the roots of field-grown transgenic Brassica napus cv. Quest, compared to the nontransgenic B. napus cv. Excel and B. rapa cv. Parkland. FEMS Microbiol. Ecol. 29: 263-272.

Smit, E.; van Elsas, J.D.; van Veen, J.A.; de Vos, W.M. 1991: Detection of plasmid transfer from Pseudomonas fluorescens to indigenous bacteria in soil by using bacteriophage R2f for donor counterselection. Appl. Enviro. Micro. 57: 3482-3488.

Stotzky, G.J. 2000: Persistence and biological activity in soil of insecticidal proteins from Bacillus thuringiensis and of bacterial DNA bound on clays and humic acids. J. Environ. Qual. 29: 691-705. 